\title{
Study of Frequency and Characteristics of Red Blood Cell Alloimmunization in Thalassemic Patients: Multicenter Study from Palestine
}

\author{
Adham Abu Taha ${ }^{1}$, ${ }^{1}$ Ahmad Yaseen, ${ }^{1}$ Sa'd Suleiman, ${ }^{1}$ Omar Abu Zenah, ${ }^{1}$ Hammam Ali ${ }^{D}{ }^{2}$ \\ Rania Abu Seir, ${ }^{2}$ and Khaled Younis ${ }^{2}$ \\ ${ }^{1}$ College of Medicine and Health Sciences, An-Najah National University, Nablus, State of Palestine \\ ${ }^{2}$ Department of Medical Lab Sciences, Faculty of Health Professions, Al-Quds University, Jerusalem, State of Palestine \\ Correspondence should be addressed to Adham Abu Taha; aabutaha@najah.edu
}

Received 15 June 2019; Accepted 26 August 2019; Published 12 November 2019

Academic Editor: Debra A. Hoppensteadt

Copyright (c) 2019 Adham Abu Taha et al. This is an open access article distributed under the Creative Commons Attribution License, which permits unrestricted use, distribution, and reproduction in any medium, provided the original work is properly cited.

\begin{abstract}
Background. $\beta$-Thalassemia is a common inherited hemolytic disorder in Palestine. Red blood cell (RBC) transfusion is the principal treatment but it may cause RBC alloimmunization. This study was conducted to determine the prevalence and characteristics of RBC alloimmunization among thalassemic patients in northern governorates of Palestine. Methods. A prospective multicenter observational study was conducted in the thalassemia transfusion centers in the northern governorates of Palestine. The study included 215 thalassemia patients who received regular blood transfusions. Clinical and transfusion records of patients were examined. Antibody screening and identification was conducted using the microcolum gel technique. Results. Two hundred fifteen patients were included in the study. More than half (52.1\%) of the patients were males. The median age of patients was 18 years (range: $12-24$ years). The most frequent blood group was A (40.5\%). Alloantibodies were detected in $12.6 \%$ of patients. Anti-D (33.3\%), anti-K (25.9\%) and anti-E (14.8\%) were the most commonly isolated antibodies. There was no association between age, sex, starting age of transfusion, number of transfused units, history of splenectomy and alloimmunization. Conclusions. Anti-Rh and anti-K antibodies were common among this cohort of patients. Age, sex, starting age of transfusion, number of transfused units, and history of splenectomy could not predict the occurrence of alloimmunization.
\end{abstract}

\section{Introduction}

Beta thalassemia ( $\beta$-thalassemia) is the most common inherited hemolytic disorder caused by partial or complete defect in globin chain $[1,2]$. Patients with $\beta$-thalassemia-major need regular blood transfusions throughout life. Blood is usually administered every $2-5$ weeks in order to maintain the hemoglobin level between 9.5 and $10.5 \mathrm{~g} / \mathrm{dl}[3,4]$.

Alloimmunization to red cell antigens is one of the important complications of chronic blood transfusion in addition to iron overload and transfusion-transmitted infections $[5,6]$. It can complicate transfusion therapy by causing delayed transfusion reactions and difficulties in finding compatible blood which may lead to increased morbidity and mortality in transfusion-dependent patients [7-9].
Alloimmunization rates among multiply-transfused thalassemia patients range from $2.5 \%$ to $42 \%$ in different regions of the world. The most common RBCs alloantibodies reported were ones against the Rhesus $(\mathrm{Rh})$ and Kell antigens $[10,11]$. There is only one previously published report about alloimmunization in multiply-transfused patients in Palestine. Samarah et al. reported the frequency of alloimmunization among sickle cell disease patients (7.76\%) and the most frequent antibody was anti-K followed by anti-E antibodies [12].

The objectives of this study were to [1] assess alloimmunization among thalassemia patients in the northern governorates of Palestine, [2] determine the specificity of detected antibodies, and [3] to assess the possible association between previously reported risk factors and the development of alloimmunization. 


\section{Methods}

A prospective multicenter observational study was conducted in all thalassemia transfusion centers in the northern governorates of Palestine (West Bank). Palestine consists of northern and southern governorates (The West Bank and Gaza Strip, respectively).

\section{Patients}

The total number of transfusion-dependent thalassemic patients in the northern governorates is 500 (verbal communication from the TPFS-Palestine). In total, 215 thalassemic patients ( $\beta$-thalassemia major and $\beta$-thalassemia intermedia) were conveniently selected and evaluated. Transfusiondependent patients who received at least 10 blood transfusions, of any age or gender were included. Multiply transfused patients with known connective tissue disease or any other autoimmune diseases were excluded.

\section{Data Collection}

Demographic and clinical information such as age, gender, status of the spleen, age of starting transfusion and number of transfused units were obtained directly from the participants (or their legal guardians) or from their medical files.

\section{Laboratory Methods}

Blood samples were collected from all patients. Plasma was screened for the presence of alloantibodies by using commercial three-cell panel (ID-Diacell I-II-II, Bio-Rad, Switzerland). The antibody specificity of all positive samples was determined using a commercial 11-cell identification panel (ID-DiaPanel, Bio-Rad, Switzerland).

\section{Statistical Analysis}

Statistical analysis was performed using the Statistical Package for the Social Science (SPSS) software (version 23.0; SPSS Inc., Chicago, IL, USA). Analysis included descriptive statistics, frequency distribution, mean, and standard deviation calculations. The relationship between alloimmunization and age, starting age of transfusion, and number of transfusions was assessed by Mann-Whitney $U$ test. Chi-Square or Fisher's exact test was used to assess the association between gender and splenectomy and risk of alloimmunization. All reported $p$ values are two-sided, with a priori significance level of 0.05 .

\section{Ethical Considerations}

Informed consent was obtained from patients or their legal guardians. The study was approved by Institutional Review Board committee at An-Najah National University, the research ethics committee at Al-Quds University and the Palestine Ministry of Health.
TABLE 1: Patients' characteristics.

\begin{tabular}{lcc}
\hline Variable & Frequency & Percentage \\
\hline Gender & 112 & 52.1 \\
Male & 103 & 47.9 \\
Female & 195 & \\
\hline Diagnosis & 20 & 90.7 \\
Beta thalassemia major & 9.3 \\
Beta thalassemia intermedia & & \\
Blood group & 87 & 40.5 \\
A & 35 & 16.3 \\
B & 81 & 37.7 \\
O & 12 & 5.6 \\
AB & & \\
Rh (D) & 192 & 89.3 \\
Positive & 23 & 10.7 \\
Negative & & \\
Splenectomy & 102 & 47.4 \\
Yes & 113 & 52.6 \\
No & & \\
\hline Antibody screening & 27 & 12.6 \\
Positive & 188 & 87.4 \\
Negative & &
\end{tabular}

TABLE 2: Transfusion history.

\begin{tabular}{lcc}
\hline & Mean \pm SD & Range \\
\hline Age & $19.02 \pm 10.2$ & $2-70$ \\
Transfusion starting age (month) & $16.55 \pm 27$ & $1-300$ \\
Number of transfusions & $158.8 \pm 144.2$ & $10-676$ \\
\hline
\end{tabular}

TABLE 3: Antibody specificity.

\begin{tabular}{lc}
\hline Type & $n(\%)$ \\
\hline Anti-D & $9(33.3)$ \\
Anti-K & $7(25.9)$ \\
Anti-E & $4(14.8)$ \\
Anti-C & $1(3.7)$ \\
Anti-Kpa & $1(3.7)$ \\
Anti-Jka & $1(3.7)$ \\
Anti-E \& anti-K & $1(3.7)$ \\
Anti-E \& anti-Jka & $1(3.7)$ \\
Anti-C \& anti-D & $1(3.7)$ \\
Anti-E, anti-Jka \& anti-K & $1(3.7)$ \\
Total & $27(100)$ \\
\hline
\end{tabular}

\section{Results}

8.1. Patient Characteristics. During the study period, 215 patients were interviewed. There were 112 (52.1\%) male and 103 (47.9) female patients (Table 1). The mean age was $19.02 \pm 10.2$ with a range from 2 to 70 years (Table 2$)$. One hundred ninety-two patients $(89.3 \%)$ were $\mathrm{Rh}(\mathrm{D})$ positive. The most frequent blood type was A $(87 ; 40.5 \%)$ followed by $\mathrm{O}(81 ; 37.7 \%), \mathrm{B}(35 ; 16.3 \%)$, and $\mathrm{AB}(12 ; 5.6 \%)$. One 
TABLE 4: Contribution of potential of risk factors to alloimmunization.

\begin{tabular}{lccc}
\hline Variable & Alloimmunized median (Q1-Q3) or $n(\%)$ & $\begin{array}{c}\text { Nonalloimmunized median (Q1-Q3) or } \\
n(\%)\end{array}$ & $p$-value \\
\hline Age (years) & $18(12-24)$ & $18(12-24)$ & 0.832 \\
Transfusion starting age (month) & $12(6-12)$ & $12(5.3-15.5)$ & 0.875 \\
Number of transfusions & $107(71-329)$ & $102(68-200)$ & 0.42 \\
\hline Gender & $10(37.0)$ & $102(54.3)$ & 0.103 \\
Male & $17(63.0)$ & $86(45.7)$ & 0.539 \\
Female & $11(40.7)$ & $91(48.4)$ & \\
History of splenectomy & $16(59.3)$ & $97(51.6)$ & \\
Yes & & & \\
No & & & \\
\hline
\end{tabular}

hundred ninety-five patients $(90.7 \%)$ had $\beta$-thalassemia major and twenty $(9.3 \%)$ had $\beta$-thalassemia intermedia. Less than half $(102 ; 47.4 \%)$ of the patients had their spleen removed (Table 1). The mean age of starting blood transfusion was $16.55 \pm 27$ years with a range of 1 month to 25 years. The mean number of received blood units was $158.8 \pm 144.2$ with a range of $10-676$ units of packed red blood cells (Table 2).

8.2. Alloantibody Screening and Specificity. Twenty-seven patients (12.6\%) were alloimmunized. Twenty-three patients had a single alloantibody (85.2\%) and four patients (14.8\%) had multiple antibodies each (three patients had two antibodies each and one had three antibodies). The most frequent antibody was anti-D $(9 ; 33.3 \%)$ followed by anti-K $(7 ; 25.9 \%)$, anti-E $(4 ; 14.8 \%)$ and anti-Kpa, anti-C, anti-Jka ( 1 ; $3.7 \%$ each) (Table 3 ).

8.3. Assessment of Predictors for Alloimmunization. Age of patients, starting age of transfusion, number of transfused blood units, gender, and splenectomy were not significantly different among alloimmunized and nonalloimmunized patients (Table 4).

\section{Discussion}

This study was conducted to determine the frequency and specificity of alloantibodies among transfusion-dependent thalassemia patients in the northern governorates. On the other hand, we assessed the association of previously reported risk factors and the development of alloimmunization in our cohort.

This is the first study to assess the frequency of alloantibodies among thalassemia patients in Palestine. The rate of alloamunization was $12.6 \%$. Higher frequency of alloimmunization was reported from the province of Alexandria in Egypt (42.5\%) [11], Taiwan (37\%) [13], Kuwaiti Arabs (30\%) [14], Saudi Arabia (22.06\%) [15], Egypt (22.8\%, 19.5\% in limited donor program) [16], India (18.8\%) [17] and Iran (17.9\%, $16.3 \%) ;[18,19]$.

Other studies reported lower frequency of alloimmunization among transfusion-dependent thalassemia patients. Albania (11.8\%); [20], Oman (9.3); [21], Malaysia (8.6\%); [8],
Pakistan (8.6\%); [22], Jammu region in India (8.5\%); [23], Fayoum province in Egypt (7.98\%); [24], Tunis (7.7\%); [25], southern Iran (5.3\%); [26], Iraqi Kurdistan (4.5\%); [27] and Karachi-Pakistan (3.75\%); [28].

The most frequent alloantibodies were anti-D, anti-K and anti-E (33.3\%, $25.9 \%$, and $14.8 \%$ respectively). This finding is similar to those reported in Egypt, India, and Pakistan, where antibodies against the Rh-system and Kell system antigens [22, $27,29,30]$ were the most frequent. In a study done by Ameen et al. [14], it was found that alloantibodies against antigens from the Kell-system are the most common alloantibodies followed by those against the Rh-system in alloimmunized transfusion-dependent Arab thalassemia patients in Kuwait, where anti-K was the most common followed by anti-E [14]. Moreover, Karimi et al. [26] and Davari in Iran [19] reported that alloantibodies belonging to the Kell-system were the most common alloantibodies. A lower anti-K frequency of $0.53 \%$ was reported in Fayoum, Egypt [24].

Predictors of alloimmunization among multiply transfused patients are still debatable. Our study showed no significant association with age and this is in agreement with Al-Mousawi et al. [27] and Elhence et al. [31]. On the other hand Al-Riyami et al. from Oman reported a significant association between age and alloimmunization [21].

Alloimmunization in splenectomized patients in our study was not statistically different from nonsplectomized patients. Several studies reported insignificant association between splenectomy and alloimmunization [21, 26, 27, $30,31]$. Other studies reported a significant association $[24,29,32]$.

Age at initiation of transfusion was not significantly different among alloimmunized and non-alloimmunized patients. This is in agreement with Karimi et al., Amin et al., and Elhence et al. $[18,26,31]$. Other reports showed a significant association [24, 27].

Contrary to other reports $[21,23,26,29,32]$, we did not find a significant association between the numbers of transfused blood units the development of alloimmunization and this is in agreement with Al-Mousawi et al. [27].

Similar to our study, few reports did not find a significant relationship between alloimmunization and gender [21, 23, 27]. Other reports found female gender [24, 33] or male [29] as a risk factor for alloimmunzion. 


\section{Limitations of the Study}

The incidence of thalassemia in Palestine is dwindling and this is due to the premarital screening program enforced by the Palestine Ministry of Health for beta thalassemia carriers and discouraging marriage between carriers. Clinical data were collected from a computerized system in the Palestinian Ministry of Health, but some data such as age of starting transfusion, transfusion frequency and number of transfused units was unavailable. Therefore, age of starting transfusion and transfusion frequency were estimated by patients or guardians and the number of transfused units was estimated by calculations from the age of starting transfusion and transfusion frequency.

\section{Conclusions}

The high frequency of anti-D antibodies highlights the need to implement strict quality control programs in the local blood banks to test for weak D positive antigens. Red cell alloimmunization in transfusion dependent thalassemia patients can be minimized by phenotyping for Rh and Kell system.

\section{Data Availability}

Data supporting the findings will be provided upon request.

\section{Conflicts of Interest}

The authors declare that they have no conflicts of interest.

\section{References}

[1] A. Cao and R. Galanello, "Beta-thalassemia," Genetics in Medicine, vol. 12, no. 2, pp. 61-76, 2010.

[2] M. Angastiniotis and B. Modell, "Global epidemiology of hemoglobin disorders," Annals of the New York Academy of Sciences, vol. 850, no. 1, pp. 251-269, 1998.

[3] H. L. Muncie and J. Campbell, "Alpha and beta thalassemia," American Family Physician, vol. 80, no. 4, pp. 339-344, 2009.

[4] M. D. Cappellini, A. Cohen, J. Porter, A. Taher, and V. Viprakasit, Guidelines for the Management of Transfusion Dependent Thalassaemia (TDT), Thalassaemia International Federation, Nicosia, CY, 3rd edition, 2014, http://www.ncbi.nlm.nih.gov/ books/NBK269382/.

[5] A. El-Beshlawy and M. El-Ghamrawy, "Recent trends in treatment of thalassemia," Blood Cells, Molecules, and Diseases, vol. 76, pp. 53-58, 2019.

[6] S. Sharma, P. Sharma, and L. N. Tyler, "Transfusion of blood and blood products: indications and complications," American Family Physician, vol. 83, no. 6, pp. 719-24, 2011.

[7] F. Bilwani, G. N. Kakepoto, S. N. Adil, M. Usman, F. Hassan, and M. Khurshid, "Frequency of irregular red cell alloantibodies in patients with thalassemia major: a bicenter study," JPMA Journal of the Pakistan Medical Association, vol. 55, no. 12, pp. 563-565, 2005.
[8] M. N. N. Haslina, N. F. M. Ariffin, I. I. Hayati, and H. Rosline, "Red cell immunization in multiply transfused Malay thalassemic patients," Southeast Asian Journal of Tropical Medicine and Public Health, vol. 37, no. 5, pp. 1015-1020, 2006.

[9] K. Hassan, M. Younus, N. Ikram, L. Naseem, and H. Zaheer, "Red cell alloimmunization in repeatedly transfused thalassemia major patients," International Journal of Pathology, vol. 1, Article ID 2, 2004 .

[10] S. T. Singer, V. Wu, R. Mignacca, F. A. Kuypers, P. Morel, and E. P. Vichinsky, "Alloimmunization and erythrocyte autoimmunization in transfusion-dependent thalassemia patients of predominantly asian descent," Blood, vol. 96, no. 10, pp. 3369-3373, 2000.

[11] J. M. A. S. Obaid, S. Y. Abo El-Nazar, A. M. Ghanem, A. S. ElHadidi, and B. H. M. Mersal, "Red blood cells alloimmunization and autoimmunization among transfusion-dependent betathalassemia patients in Alexandria province, Egypt," Transfusion and Apheresis Science, vol. 53, no. 1, pp. 52-57, 2015.

[12] F. Samarah, M. A. Srour, D. Yaseen, and K. Dumaidi, "Frequency of red blood cell alloimmunization in patients with sickle cell disease in Palestine," Advances in Hematology, vol. 2018, Article ID 5356245, pp. 1-7, 2018.

[13] L.-Y. Wang, D.-C. Liang, H.-C. Liu et al., "Alloimmunization among patients with transfusion-dependent thalassemia in Taiwan," Transfusion Medicine, vol. 16, no. 3, pp. 200-203, 2006.

[14] R. Ameen, S. Al-Shemmari, S. Al-Humood, R. I. Chowdhury, O. Al-Eyaadi, and A. Al-Bashir, "RBC alloimmunization and autoimmunization among transfusion-dependent Arab thalassemia patients," Transfusion (Paris), vol. 43, no. 11, pp. 1604-1610, 2003.

[15] A. G. M. A. Gader, A. K. Al Ghumlas, and A. K. M. Al-Momen, "Transfusion medicine in a developing country - alloantibodies to red blood cells in multi-transfused patients in Saudi Arabia," Transfusion and Apheresis Science, vol. 39, no. 3, pp. 199-204, 2008.

[16] A. S. El Danasoury, D. G. Eissa, R. M. Abdo, and M. S. Elalfy, "Red blood cell alloimmunization in transfusion-dependent Egyptian patients with thalassemia in a limited donor exposure program," Transfusion (Paris), vol. 52, no. 1, pp. 43-47, 2012.

[17] C. Chaudhari, "Red cell alloantibodies in multiple transfused thalassaemia patients," Medical Journal Armed Forces India, vol. 67, no. 1, pp. 34-37, 2011.

[18] M. Amin, "Prevalence of alloimmunization against RBC antigens in thalassemia major patients in South East of Iran," Journal of Blood Disorders \& Transfusion, vol. 04, no. 04, pp. 2155-9864, 2013, https://www.omicsonline.org/prevalenceof-alloimmunization-against-rbc-antigens-in-thalassemiamajor-patients-in-south-east-of-iran-2155-9864.1000147. php?aid=15592.

[19] K. Davari and M. S. Soltanpour, "Study of alloimmunization and autoimmunization in Iranian $\beta$-thalassemia major patients," Asian Journal of Transfusion Science, vol. 10, no. 1, pp. 88-92, 2016.

[20] I. Seferi, M. Xhetani, M. Face, G. Burazeri, E. Nastas, and G. Vyshka, "Frequency and specificity of red cell antibodies in thalassemia patients in Albania," International Journal of Laboratory Hematology, vol. 37, no. 4, pp. 569-574, 2015.

[21] A. Z. Al-Riyami, A. Al-Muqbali, S. Al-Sudiri et al., "Risks of red blood cell alloimmunization in transfusion-dependent $\beta$-thalassemia in Oman: a 25 -year experience of a university 
tertiary care reference center and a literature review," Transfusion, vol. 58, no. 4, pp. 871-878, 2018.

[22] U. Zaidi, M. Borhany, S. Ansari et al., "Red cell alloimmunisation in regularly transfused beta thalassemia patients in Pakistan," Transfusion Medicine, vol. 25, no. 2, pp. 106-110, 2015.

[23] A. Dogra, M. Sidhu, R. Kapoor, and D. Kumar, "Study of red blood cell alloimmunization in multitransfused thalassemic children of Jammu region," Asian Journal of Transfusion Science, vol. 9, no. 1, pp. 78-81, 2015.

[24] A. M. Abdelrazik, S. M. Elshafie, M. N. El Said et al., "Study of red blood cell alloimmunization risk factors in multiply transfused thalassemia patients: role in improving thalassemia transfusion practice in Fayoum, Egypt," Transfusion, vol. 56, no. 9, pp. 2303-2307, 2016.

[25] N. Guirat-Dhouib, M. Mezri, H. Hmida et al., "High frequency of autoimmunization among transfusion-dependent Tunisian thalassaemia patients," Transfusion and Apheresis Science, vol. 45, no. 2, pp. 199-202, 2011.

[26] M. Karimi, P. Nikrooz, S. Kashef, N. Jamalian, and Z. Davatolhagh, "RBC alloimmunization in blood transfusiondependent beta-thalassemia patients in southern Iran," International Journal of Laboratory Hematology, vol. 29, no. 5, pp. 321-326, 2007.

[27] M. M. N. Al-Mousawi, N. A. S. Al-Allawi, and R. Alnaqshabandi, "Predictors of red cell alloimmunization in kurdish multi transfused patients with hemoglobinopathies in Iraq," Hemoglobin, vol. 39, no. 6, pp. 423-426, 2015.

[28] M. Usman, "Frequency of red cell alloimmunization among patients with transfusion dependent beta thalassemia in Pakistan," International Journal of Hematology and Oncology, vol. 21, no. 3, pp. 166-169, 2011.

[29] E. Hussein, N. Desooky, A. Rihan, and A. Kamal, "Predictors of red cell alloimmunization in multitransfused Egyptian patients with $\beta$-thalassemia," Archives of Pathology \& Laboratory Medicine, vol. 138, no. 5, pp. 684-688, 2014.

[30] S. Pahuja, M. Pujani, S. K. Gupta, J. Chandra, and M. Jain, "Alloimmunization and red cell autoimmunization in multitransfused thalassemics of Indian origin," Hematology, vol. 15, no. 3, pp. 174-177, 2010.

[31] P. Elhence, A. Solanki, and A. Verma, "Red blood cell antibodies in thalassemia patients in northern india: risk factors and literature review," Indian Journal of Hematology and Blood Transfusion, vol. 30, no. 4, pp. 301-308, 2014.

[32] A. V. Romphruk, P. Simtong, C. Butryojantho et al., "The prevalence, alloimmunization risk factors, antigenic exposure, and evaluation of antigen-matched red blood cells for thalassemia transfusions: a 10-year experience at a tertiary care hospital," Transfusion, vol. 59, no. 1, pp. 177-184, 2019.

[33] M. P. Bauer, J. Wiersum-Osselton, M. Schipperus, J. P. Vandenbroucke, and E. Briët, "Clinical predictors of alloimmunization after red blood cell transfusion," Transfusion, vol. 47, no. 11, pp. 2066-2071, 2007. 


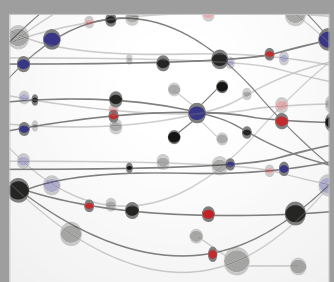

The Scientific World Journal
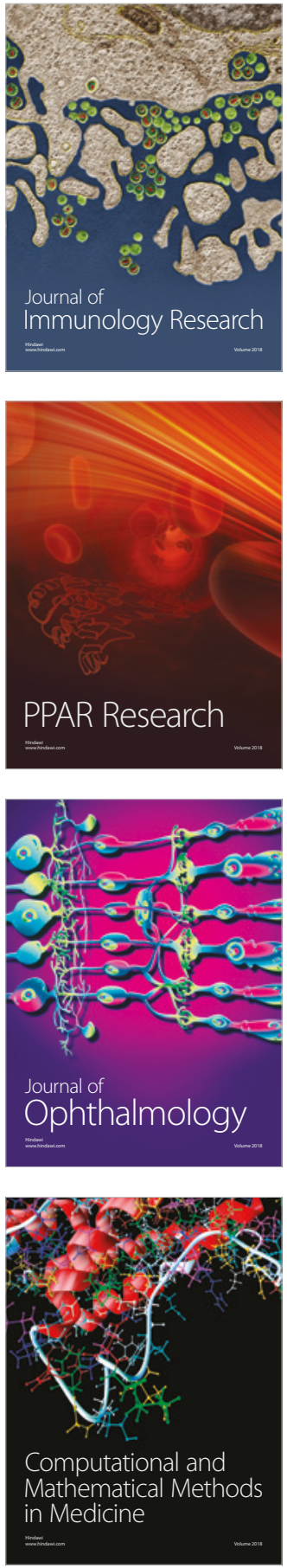

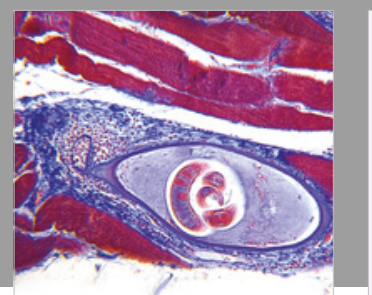

Gastroenterology Research and Practice

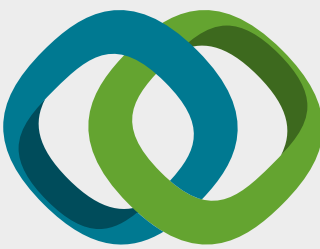

\section{Hindawi}

Submit your manuscripts at

www.hindawi.com
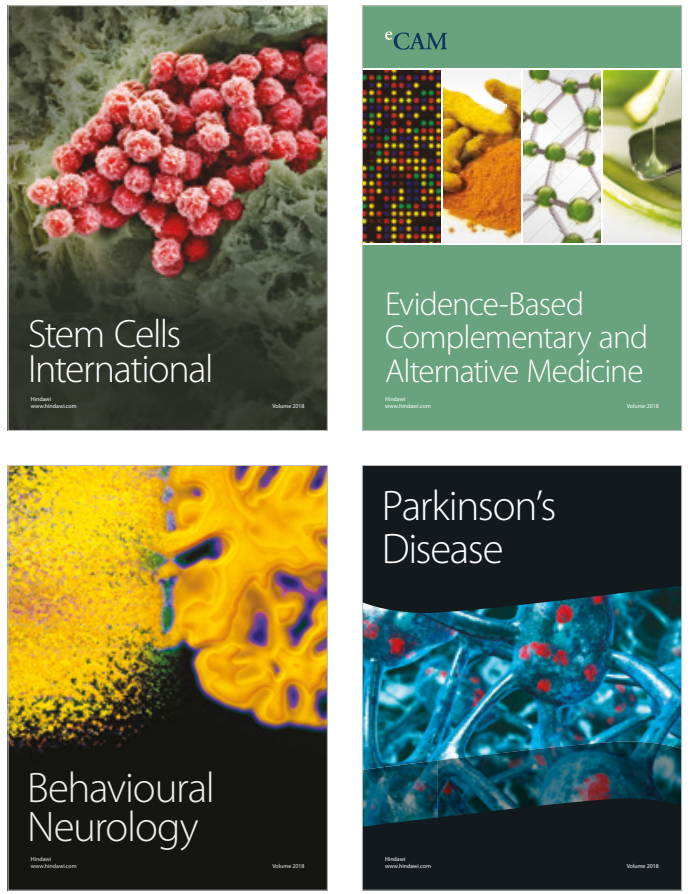

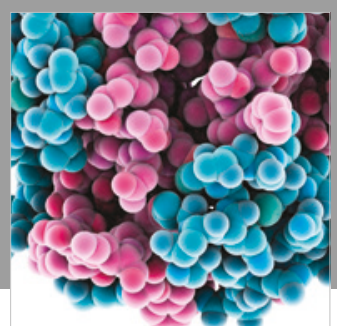

ournal of

Diabetes Research

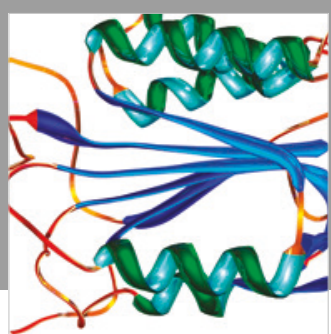

Disease Markers
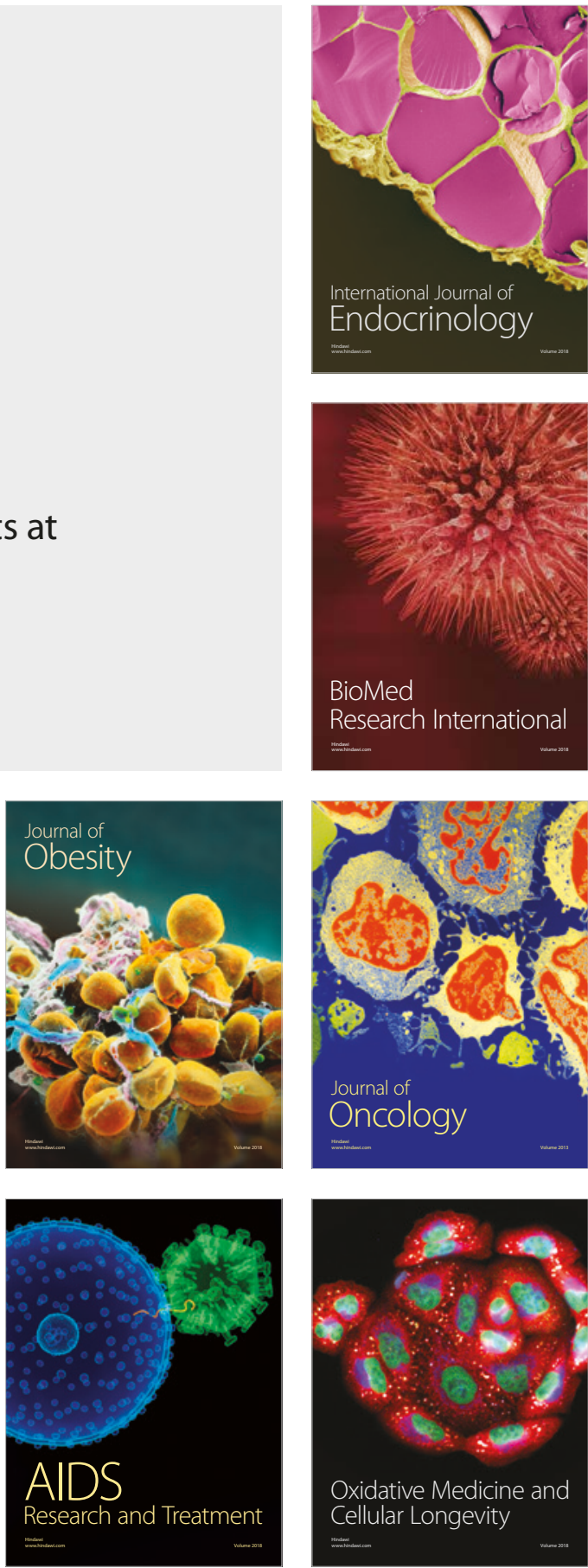